\title{
The Improvement and application of elevation measurement method with total station
}

\author{
Yiteng $\mathrm{Xu}^{1,2^{*}}$, Xin $\mathrm{Zhao}^{3}$, Hewen $\mathrm{Liu}^{1,2}$, Feng $\mathrm{Xu}^{4}$, Xiaoqiang Wang ${ }^{1,2}$ \\ ${ }^{1}$ Tianjin Port Engineering Institute Co., Ltd. of CCCC First Harbor Engineering Co., Ltd., Key Laboratory of Geotechnical Engineering, \\ Ministry of Communications, Key Laboratory of Geotechnical Engineering of Tianjin, Tianjin 300222, China; \\ ${ }^{2}$ CCCC First Harbor Engineering Co., Ltd., Tianjin 300461, China; \\ ${ }^{3}$ Guangzhou Urban Renewal Data Center, Guangzhou 510030, China; \\ ${ }^{4}$ China Railway Liuyuan Group Co., Ltd., Tianjin 300308, China;
}

\begin{abstract}
In this paper, by analyzing the limitations of the traditional trigonometric elevation method, and on the basis of establishing a mathematical model of trigonometric elevation, a convenient and fast trigonometric elevation method without instrument height and prism height is improved, and the operation steps of the method are introduced in detail. The accuracy analysis was evaluated and the method was applied to actual engineering. The results show that under the premise of ensuring the measurement accuracy, this method not only reduces the range of measurement error sources, but also improves the measurement efficiency.
\end{abstract}

\section{Introduction}

In the process of elevation survey or vertical displacement monitoring, due to the low accuracy of trigonometric leveling, people used conventional measuring instruments and leveling methods in road elevation survey or linear engineering monitoring. The total station had been widely used in engineering measurement and engineering monitoring. The total station integrated electronic the odolite, electro-optical distance measurement and data recording, which made its ranging and angle measuring accuracy greatly improved and had the possibility to use it into road elevation measurement. At the same time, the total station had the advantages of fast speed and high efficiency, and it could meet different accuracy of road elevation measurements with different observation methods.

The two methods of leveling and trigonometric leveling in elevation survey had their own characteristics, but both of them still had short comings. Leveling is a method of direct height measurement. The accuracy of elevation difference measurement was high, but it was greatly affected by the terrain fluctuation. In addition, the field work was heavy and the work efficiency was low. Trigonometric leveling was a method of indirect height measurement. Although it was not affected by terrain fluctuation and was widely used in large-scale surveying and mapping and linear engineering, its accuracy was low. In the process of measurement each time, the instrument height and prism height must be measured. The process was complex and involves a lot of instrument data, which increased the source of error [1].
The method of trigonometric leveling was improved through engineering practice and exploration. It combined the advantages of leveling and trigonometric leveling. It also combined the characteristics of arbitrary setting of levelling in the survey and the height of the prism and the instrument didn't need to be measured. Without the height difference error caused by instrument height and prism height in the trigonometric leveling process, the measurement accuracy got improved. In the coordinate measurement of road engineering, the surveying and mapping technology with the instrument height and prism height can improve the accuracy of engineering monitoring, coordinate measurement and coordinate lofting, it can also make the measurement process more simple, convenient and faster, it was significative to engineering monitoring and measurement.

\section{Mathematical model of total station trigonometric leveling}

If the control points were in the mountainous area or on the high-rise building, it would be slow and difficult to measure the height of the points by leveling method. In the traditional engineering survey, it usually used the distance and the elevation difference between the two points, which measured by trigonometric leveling principle, to obtain the elevation of the point to be calculated. Because this method had certain error in the process of the instrument height and the prism height were measured. It leaded to the result of trigonometric leveling accuracy was lower than the level measurement. It was usually only used in low-level elevation control measurement [2].

\footnotetext{
* Corresponding author: 18710804642@163.com
} 
As shown in Figure 1, in order to measure the elevation difference between points $\mathrm{A}$ and $\mathrm{B}$, a station was set at point $\mathrm{O}$, $\mathrm{i}$ was the instrument height, $\mathrm{t}$ was the prism height, Ho was the station elevation and $\mathrm{H}_{2}$ was the elevation difference between the prism of point $\mathrm{B}$ and the collimation axis of the total station.

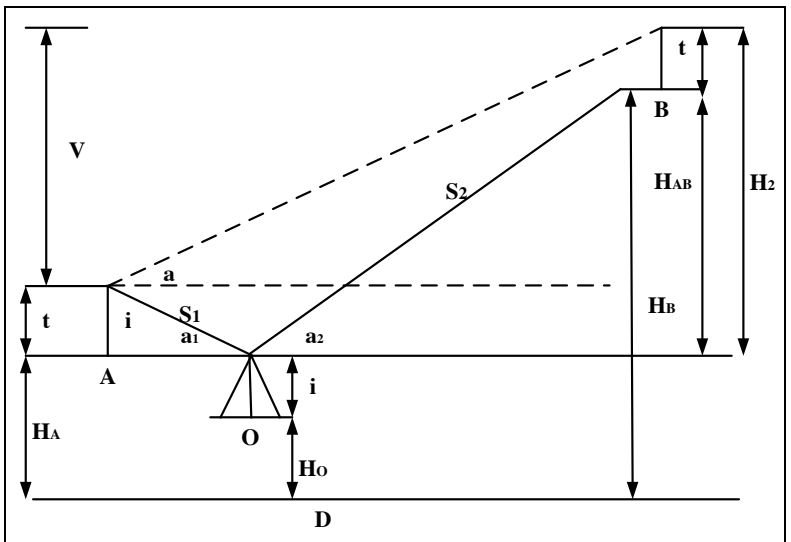

Fig. 1. Schematic diagram of trigonometric levelling

Then the elevation difference of $\mathrm{H}_{\mathrm{AB}}$ was:

$$
H_{A B}=S_{2} \bullet \operatorname{Sin} \alpha_{2}-S_{1} \bullet \operatorname{Sin} \alpha_{1}
$$

Therefore, the elevation difference $\mathrm{H}_{\mathrm{AB}}$ between the two points of $\mathrm{A}$ and $\mathrm{B}$ was related to the size of the vertical angle between the two points, and it had nothing to do with the instrument height and the prism height. So through the method of increased the redundant observation times, we could eliminate the error caused by measuring the instrument height and the prism height when we used the trigonometric leveling method to measure the elevation difference.

\section{Traditional trigonometric leveling method and accuracy analysis}

In order to determine the elevation difference between point $\mathrm{A}$ and $\mathrm{B}$, set a station at point $\mathrm{A}$, set a prism at point $\mathrm{B}$, observed the vertical angle a, and measured the instrument height $\mathrm{i}$ and prism height $\mathrm{v}$. If the horizontal distance between point $\mathrm{A}$ and $\mathrm{B}$ was $\mathrm{D}$, the elevation difference of $\mathrm{H}_{\mathrm{AB}}$ was:

$$
\begin{gathered}
H_{A B}=V+\mathrm{i}-\mathrm{t} \\
H_{B}=\mathrm{H}_{\mathrm{A}}+D \tan \alpha+\mathrm{i}-\mathrm{t}+\mathrm{f}
\end{gathered}
$$

This basic formula was based on the premises that the horizontal plane was the datum and the line of sight was a straight line [3]. Therefore, only when the distance between two points $\mathrm{A}$ and $\mathrm{B}$ was close, the measured elevation was relatively accurate. When the distance was far, the influence of earth curvature and atmospheric refraction must be considered. In the traditional method, the station must be on a known point, and the height of the instrument and the prism must be measured.

Because the calculation of elevation difference with the trigonometric leveling method was according to the instrument height and the prism height, it must consider the influence of their error.
Set $m_{i}$ as the mid-reading error of the instrument height and $\mathrm{m}_{\mu}$ as the mid-reading error of the prism height. In the same way, so used the trigonometric leveling method could get the mean error $\mathrm{m}_{\Delta \mathrm{h}}$ between the elevation difference of points $\mathrm{A}$ and $\mathrm{B}$, as follows:

$\mathrm{m}_{\Delta \mathrm{h}}= \pm \sqrt{\left(\sin ^{2} \alpha_{1}+\sin ^{2} \alpha_{2}\right) \mathrm{m}_{\mathrm{s}}^{2}+\left(\mathrm{s}_{1} \cos ^{2} \alpha_{1}+\mathrm{s}_{2} \cos ^{2} \alpha_{2}\right) \mathrm{m} \alpha^{2}+\mathrm{mi}^{2}+\mathrm{m} \mu^{2}}$

\section{Trigonometric leveling method and accuracy analysis without measuring instrument and prism height}

If the total station could be set up at will, liked the level, instead of being set on the known elevation point and didn't have to measure the instrument height or prism height at the same time, used the trigonometric leveling principle to measure the elevation of the point, then the speed of measurement will be increased under the premise of ensuring accuracy.

\subsection{Operation method}

As shown in Figure 1, as sumed that the elevation of point $B$ was known and the elevation of point $A$ was unknown used the total station to measure the elevation of other points to be measured.

$$
H_{A}=\mathrm{H}_{\mathrm{B}}-(D \tan \alpha+\mathrm{i}-\mathrm{t}+\mathrm{f})
$$

Dtan $\alpha$ was $V$, which can be directly measured by total station. $\mathrm{H}_{\mathrm{A}}, \mathrm{t}$ and $\mathrm{f}$ are constant and $\mathrm{i}$ could also be constant at the same point. So:

$$
H_{A}+\mathrm{i}-\mathrm{t}=\mathrm{H}_{\mathrm{B}}-D \tan \alpha=W
$$

Based on the above assumption, it can be seen from equation (6) that $\mathrm{HA}+\mathrm{i}-\mathrm{t}$ was also constant, and the value of it could be calculated, then instead it with W.

The specific operation steps were as follows:

a. Set the instrument at any point which position shall be able to see through with the known elevation point.

b. Used the instrument to aim at the known elevation point, measure the value of $\mathrm{V}$, and calculated the value of W. (At this time, the constants related to the elevation measurement of the instrument, such as the elevation of the measuring station, the height of the instrument and the height of the prism, were all arbitrary values, which need not to be set before the measurement.)

c. Reset the elevation of the instrument station to W, and set the instrument height and prism height to zero.

d. Aimed at the point in question and measure the elevation.

\subsection{Accuracy analysis}

Let $\mathrm{m}_{\mathrm{s}}$ was the mean square error of the slope distance between the instrument and the prism, and $\mathrm{m}_{\alpha}$ was the mean square error of the vertical angle. According to the law of error propagation, the mean square error $m_{\Delta h}$ of the elevation difference between points $\mathrm{A}$ and $\mathrm{B}$ is: 


$$
\mathrm{m}_{\Delta \mathrm{h}}= \pm \sqrt{\sin ^{2} \alpha_{1} \mathrm{~m}_{\mathrm{s} 1}^{2}+\sin ^{2} \alpha_{2} \mathrm{~m}_{\mathrm{s} 2}^{2}+\mathrm{s}_{1} \cos ^{2} \alpha_{1} \mathrm{~m}_{\alpha 1}^{2}+\mathrm{s}_{2} \cos ^{2} \alpha_{2} \mathrm{~m}_{\alpha 2}^{2}}
$$

Equal precision observation is adopted in the measurement, $\mathrm{m}_{\alpha 1}=\mathrm{m}_{\alpha 2}=\mathrm{m}_{\alpha}, \mathrm{m}_{\mathrm{s} 1}=\mathrm{m}_{\mathrm{s} 2}=\mathrm{m}_{\mathrm{s}}$, this method is a method of non measuring instrument height and prism height, so there is no measurement error of instrument height and prism height [4]. Then the mean square error $\mathrm{m}_{\triangle \mathrm{t}}$ of the elevation difference between points A and B was:

Table 1. Mean square errorwith total station measurement method without measuring instrument and prism height

\begin{tabular}{|c|c|c|c|c|c|}
\hline \multicolumn{2}{|c|}{ Distance(m) } & $\mathbf{1 0}$ & $\mathbf{3 0}$ & $\mathbf{5 0}$ & $\mathbf{1 0}$ \\
\hline \multirow{7}{*}{ Angle $\left({ }^{\circ}\right)$} & $1^{\circ}$ & 1.30 & 2.25 & 2.91 & 4.11 \\
\cline { 2 - 6 } & $2^{\circ}$ & 1.30 & 2.25 & 2.91 & 4.11 \\
\cline { 2 - 6 } & $5^{\circ}$ & 1.30 & 2.24 & 2.90 & 4.09 \\
\cline { 2 - 6 } & $10^{\circ}$ & 1.30 & 2.23 & 2.87 & 4.06 \\
\cline { 2 - 6 } & $30^{\circ}$ & 1.33 & 2.07 & 2.61 & 3.63 \\
\cline { 2 - 6 } & $45^{\circ}$ & 1.35 & 1.88 & 2.28 & 3.07 \\
\cline { 2 - 6 } & $60^{\circ}$ & 1.38 & 1.66 & 1.90 & 2.39 \\
\cline { 2 - 6 } & $65^{\circ}$ & 1.39 & 1.59 & 1.77 & 2.15 \\
\hline
\end{tabular}

According to the data analysis in the table, when the vertical angle was in the range of $30^{\circ}$ to $65^{\circ}$ and the distance was less than or equal to $100 \mathrm{~m}$, the measurement accuracy was the highest.

\subsection{Engineering Applications}

Most of the construction of highway tunnels used the total station trigoniometric leveling technology to monitor the tunnel's vault settlement. As shown in figure 2 , monitored the elevation of monitor points G1, G2 and G3, due to the complexity of the construction site environment and the big of the tunnel section elevation difference, and required to use the absolute elevation of the absolute coordinates, so it was not good for the construction of compulsory observation platform or using level, the traditional trigonometric leveling method was also not applicable. Therefore, the above-mentioned

$$
\mathrm{m}_{\Delta \mathrm{h}}= \pm \sqrt{\left(\sin ^{2} \alpha_{1}+\sin ^{2} \alpha_{2}\right) \mathrm{m}_{\mathrm{s}}^{2}+\left(\mathrm{s}_{1} \cos ^{2} \alpha_{1}+\mathrm{s}_{2} \cos ^{2} \alpha_{2}\right) \mathrm{m} \alpha^{2}}
$$

The Leica TS 60 total station was adopted in this survey, the angle measuring accuracy was $0.5 "$ and the ranging accuracy is $0.6 \mathrm{~mm}+1 \mathrm{pmm} * \mathrm{D}$. Amplify the measurement error according to the mean square error calculation formula of the total station trigoniometric leveling, instrument-free and prism-free measurement [5]. Suppose: $\mathrm{m}_{\alpha}= \pm 1$ ", $\mathrm{m}_{\mathrm{s}}= \pm 1 \mathrm{~mm}$, brought them into formula (8), and calculated the mean square error, as shown in

\begin{tabular}{|c|c|c|c|c|c|c|}
\hline \multirow{2}{*}{ Date } & \multicolumn{3}{|c|}{ Observation value } & \multirow{2}{*}{$\begin{array}{c}\text { Average } \\
\text { value } \\
(\mathrm{m})\end{array}$} & \multirow{2}{*}{$\begin{array}{c}\text { Accumulated } \\
\text { deformation } \\
(\mathbf{m m} / \mathbf{d})\end{array}$} & \multirow{2}{*}{$\begin{array}{l}\text { Accumulated } \\
\text { deformation } \\
(\mathrm{mm})\end{array}$} \\
\hline & I & II & III & & & \\
\hline $2019 / 9 / 1$ & 199.3601 & 199.3599 & 199.3603 & 199.3601 & 1 & 0.0 \\
\hline $2019 / 9 / 2$ & 199.3560 & 199.3561 & 199.3562 & 199.3561 & 4.0 & 4.0 \\
\hline $2019 / 9 / 5$ & 199.3527 & 199.3525 & 199.3523 & 199.3525 & 3.6 & 7.6 \\
\hline $2019 / 9 / 6$ & 199.3485 & 199.3486 & 199.3484 & 199.3485 & 4.0 & 11.6 \\
\hline $2019 / 9 / 7$ & 199.3449 & 199.3447 & 199.3451 & 199.3449 & 3.6 & 15.2 \\
\hline $2019 / 9 / 8$ & 199.3417 & 199.3418 & 199.3419 & 199.3418 & 3.1 & 18.3 \\
\hline $2019 / 9 / 9$ & 199.3409 & 199.3407 & 199.3405 & 199.3407 & 1.1 & 19.4 \\
\hline $2019 / 9 / 10$ & 199.3389 & 199.3389 & 199.3389 & 199.3389 & 1.8 & 21.2 \\
\hline 2019/9/11 & 199.3372 & 199.3371 & 199.3373 & 199.3372 & 1.7 & 22.9 \\
\hline 2019/9/12 & 199.3351 & 199.3350 & 199.3352 & 199.3351 & 2.1 & 25.0 \\
\hline $2019 / 9 / 13$ & 199.3340 & 199.3340 & 199.3337 & 199.3339 & 1.2 & 26.2 \\
\hline 2019/9/14 & 199.3307 & 199.3308 & 199.3303 & 199.3306 & 3.3 & 29.5 \\
\hline$\ldots \ldots$ & $\ldots \ldots$ & $\ldots \ldots$ & $\ldots \ldots$ & $\ldots \ldots$ & $\ldots \ldots$ & $\ldots \ldots$ \\
\hline
\end{tabular}
Table 1 below:

Table 2. Vault settlement monitoring data 


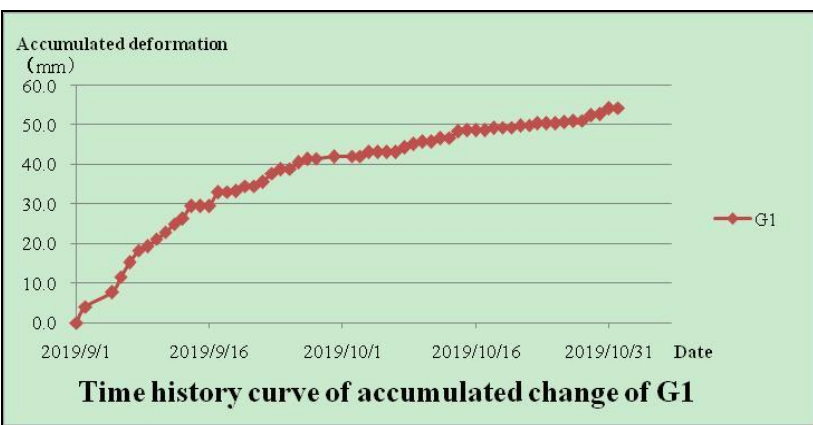

Fig. 3. Time history curve of accumulated change of G1 point

\section{Conclusions}

(1) The measuring method without measuring the height of the instrument and the prism requires that the height of the instrument and prism remain constant. Except for the height of the instrument and the prism was kept constantinthe measurement every time, the instrument, prism rod and prism measured before and after were also kept constant. Only in this way can make sure the measuring accuracy of the method.

(2)Compared with the traditional total station trigonometric leveling method, the improved measurement method reduced the measurement of the height of the instrument and the height of the prism, avoided to bring errors, reduced the workload and improved the measurement efficiency.

(3)According to the practical engineering application, as long as the technical index was properly controlled, the measurement method was correct, and the measures were in place, the elevation measurement method proposed in this paper can basically meet the accuracy requirements of tunnel crown settlement monitoring.

\section{References}

1. Cui Kezhong. Discussion on trigonometric leveling method and accuracy analysis [J]. Mapping and spatial geographic information, 2010,33 (06): 215$216+220+223$

2. Kong Pei. Instrument free high total station height measurement and its engineering application [J]. Shandong Communications Science and technology, 2007 (02): 45-47

3. Deng Hongliang. Altimetry without instrument and its application [J]. China coalfield geology, 2007 (02): 77-78+84

4. Xu Yiteng, Kou Xiaoqiang, Xu Feng, Liu Hewen. Application of Trans-sea Height Difference Transmission Method to Foundation Settlement Monitoring of Offshore Artificial Island in Deep and Middle Passage [J] .Water Transport Engineering, 2019 (06): 21-25.

5. Li Haojie, Zhang Jiawei, Zhao Yueyao. Accuracy Analysis of an Improved Triangular Elevation Measurement Method [J] .Beijing Surveying and Mapping, 2019,33 (12): 1461-1464. 